\title{
UN ARTISTA EN LA MONCLOA ${ }^{1}$
}

\author{
Jose Joaquin Jimenez Sanchez ${ }^{2}$ \\ Tengo una tendencia invencible a desconfiar de los que son \\ demasiado artistas. \\ J. Pla, Dietarios I $I^{3}, 1918$, pág. 14. \\ En la razón política no veo un placer estético, sino la \\ utilidade. \\ M. Azaña, La velada en Benicarló. Diálogo de la guerra de \\ España ${ }^{4}, 1937$, pág. 117.
}

\section{Resumen}

En este texto se trata de reflexionar al hilo de las propuestas de F. Schiller sobre la necesidad de pensar la política más allá de la ciencia y la técnica. La idea de Schiller de concebir al hombre de Estado como un artista abre el campo de la reflexión política al mundo filosófico, que constituye el espacio adecuado para enfrentarnos con las dificultades propias de nuestro tiempo.

Palabras clave: Estado Natural; Estado de Naturaleza; Estado; Hombre Físico; Hombre Moral y Nación.

\section{INTRODUCCIÓN}

No parece posible sostener que en nuestra historia reciente, y no me refiero sólo a estos últimos años, hayamos mantenido una relación fluida con la política; más bien todo lo contrario, esa relación fue siempre dificultosa. Incluso cabría decir que nuestro trato con ella ha sido áspero, tal vez porque no hemos tenido claro el papel que la belleza y el artista, y éste como artífice, han de jugar en la política. Hegel, como todo el idealismo alemán, abordó este problema de una manera diferente y, en mi opinión, más exitosa, al menos si lo contemplamos desde un punto de vista teórico. Para él, la idea de la belleza es la que "unifica todas las otras", por lo que "el acto supremo de la razón, al abarcar todas las ideas, es un acto estético, $[\ldots]$ la verdady la bondadse ven

\footnotetext{
${ }^{1}$ Resumen y breve comentario de las Cartas I-VII sobre la educación estética del hombre, en F. Schiller, Kallias. Cartas sobre la educación estética del hombre, ed. bilingüe; est. intr. de J. Feijóo; trad. y notas de J. Feijóo y J. Seca, Anthropos, Barcelona, 1990 (1793-1795), págs. 110-164.

${ }^{2}$ Personal Docente e Investigador de la Universidad de Granada, adscrito al Grupo de Investigación Sej135: Derechos Humanos Y Garantias.E-mail: jimenezs@ugr.es

${ }^{3}$ Trad. de D. Ridruejo y G. de Ros, Espasa-Calpe, Madrid, 2011 (1966, 1918).

${ }^{4}$ Ed. de M. Aragón, Castalia, Madrid, 1974.

${ }^{5}$ G. W. F. Hegel, "Primer programa de un sistema del idealismo alemán”, ;invierno 1796-97?, en Escritos de juventud, ed., int. y notas de J. M. Ripalda, trad. de J. M. Ripalda y Z. Szankay, FCE, México, 1978 (1794-1801), pág. 220.
} 
hermanadas sólo en la belleza”' ${ }^{\prime \prime}$ Dicho de manera distinta, podríamos defender que la materia exige la forma y ésta demanda aquélla; la razón requiere de la sensibilidad y viceversa; la reflexión sobre la historia reclama el sentido estético y las ideas han de transformarse en ideas estéticas, esto es, las ideas racionales tienen que convertirse "en ideas mitológicas", pues mientras no lo hagamos, esas ideas carecerán de interés para el pueblo, aunque esa mitología habrá de ser al mismo tiempo racional. Esta es la razón por la que la falta de estética nos conduce irremisiblemente a la ortodoxia. Por eso, "los [hombres] ilustrados y los no ilustrados tienen que darse la mano, la mitología tiene que convertirse en filosófica y el pueblo tiene que volverse racional, y la filosofía tiene que ser filosofía mitológica para transformar a los filósofos en filósofos sensibles"

De ahí que llame mucho la atención el juicio de autores como Pla y Azaña, uno en relación con la desconfianza ante los que son 'demasiado' - escribe-, artistas y el otro por su estrecha visión sobre la razón política a la que identifica como mera razón utilitaria. Quizá radique en esta concepción angosta de la política el fracaso de su propio proyecto, al no haber sido capaz de entender y plantear la política más allá de cualquier utilidad inmediata. Quizá sea aquí, precisamente, donde podamos aprender del idealismo alemán y de su idea de que no hay razón ni tampoco Estado sin belleza, pues éste al ser expresión de lo racional en y por sí, ha de ser al mismo tiempo y necesariamente un construcción bella, la creación de un artista -der Staatskünstler-, cuya obra de arte es la más difícil que nunca hayamos podido concebir, pues únicamente es 'a través de la belleza como se llega a la libertad'. Quizá por ello deberíamos ser capaces de saber si al alcance de nuestra vista podríamos apreciar una construcción, si es que existiera, que mereciera tales elogios. En mi opinión existe y posee la belleza propia de toda obra equilibrada, en la medida en que articula armoniosamente el interés general con los intereses particulares. Es cierto que como toda obra humana es imperfecta y requiere de su reforma y corrección, pero no tenemos aún la capacidad de sustituirla por una obra mejor. Me refiero, como no puede ser de otro modo, al denostado régimen de 1978, un régimen de libertad política.

\section{LA REVOLUCIÓN INGLESA}

Nuestra época se inicia con dos crisis políticas de enorme envergadura, la primera tiene lugar con la decapitación de Carlos I en Inglaterra, la segunda con el degüello de Luis XVI. Ambas darán lugar a reflexiones jurídico-políticas diferentes, una lo hará en torno a la monarquía absoluta y la otra sobre el poder absoluto del pueblo. Esta es la razón por la que ambas no son radicalmente distintas, pues poseen la misma raíz, la necesidad de fundamentar, al margen de las concepciones medievales, un poder político de carácter ilimitado.

\footnotetext{
${ }^{6}$ Hegel, “Primer ... Escritos ..., op. cit., pág. 220.

${ }^{7}$ Hegel, "Primer ... Escritos ..., op. cit., pág. 220.
} 
n relación con la primera, Hobbes reaccionará ante ella planteando los fundamentos políticos del orden moderno. La primera preocupación de Hobbes es la de explicar cómo se constituye, por institución o adquisición, un poder común a fin de que éste, en tanto que poder constituido, pueda establecer la ley y con ella la posibilidad de prohibir por injustos ciertos actos. "Donde no hay -dirá Hobbes- un poder común, no hay ley; y donde no hay ley, no hay injusticia”, por lo que sólo donde lo hay, habrá ley y, en consecuencia, también habrá justicia e injusticia, así como propiedad, esto es, la separación entre lo mío y lo tuyo. Hobbes plantea que la generación de un Estado se hace por medio de la erección de "un poder común que pueda defender [a los hombres] de la invasión de extraños y de las injurias entre ellos mismos, dándoles seguridad que les permita alimentarse con el fruto de su trabajo y con los productos de la tierra y llevar así una vida satisfecha"’. Ese poder común se alcanza cuando los hombres confieren "todo su poder y toda su fuerza individuales a un solo hombre o a una asamblea de hombres que, mediante una pluralidad de votos, puedan reducir las voluntades de los súbditos a una sola voluntad"10. De este modo se alcanza "una verdadera unidad de todos en una y la misma persona, unidad a la que se llega mediante un acuerdo de cada hombre con cada hombre, como si cada uno estuviera diciendo al otro: Autorizo y concedo el derecho de gobernarme a mí mismo, dando esa autoridad a este hombre o a esta asamblea de hombres, con la condición de que tú también le concedas tu propio derecho de igual manera, y les des esa autoridad en todas sus acciones" ${ }^{\prime 1}$. Así, una multitud de hombres ceden su derecho de gobernarse a sí mismos, ceden su autoridad a una persona; en definitiva, se unen en una persona, el Estado, que se encarna en el soberano, uno o varios, eso es irrelevante, que posee el poder de gobernarlos, y frente a quien los demás son súbditos. Se trata de un pacto por el que se traslada la autoridad de la multitud a la persona que se constituye y una vez constituida es soberana, sin que quienes le trasladaron su autoridad puedan recuperarla. El pacto se ha realizado en el estado de naturaleza y supone la renuncia al derecho natural que cada uno tiene a la libertad gracias al uso de la razón, que es la que nos facilita la posibilidad de establecer ciertas leyes naturales, entre las que la primera consiste en la búsqueda y mantenimiento de la paz, y que pueden resumirse en lo siguiente: "No hagas a otro lo que no quisieras que te hiciesen a ti $^{12}$. Con esto último no hemos salido aún del estado de naturaleza ${ }^{13} \mathrm{o}$ dicho con otras palabras, seguimos en el terreno moral, pues tal y como dice Hobbes, estas leyes naturales son las propias de la filosofía

\footnotetext{
8 Th. Hobbes, Leviatán. La materia, forma y poder de un Estado eclesiástico y civil, trad., prólogo y notas de C. Mellizo, Alianza Editorial, Madrid, 1989 (1651), pág. 109.

${ }^{9}$ Hobbes, Leviatán, op. cit., pág. 144.

${ }^{10}$ Hobbes, Leviatán, op. cit., pág. 144.

${ }^{11}$ Hobbes, Leviatán, op. cit., págs. 144-145.

${ }^{12}$ Hobbes, Leviatán, op. cit., pág. 132.

${ }^{13}$ Hay que tener presente que el estado de naturaleza en Hobbes está configurado de manera ambivalente, es un estado de guerra pero también lo es de razón, una situación en la que el hombre está sometido a pasiones contrapuestas. Vid., sobre ello, Hobbes, Leviatán..., op. cit., págs. 107, 109 y 141.
} 
moral como ciencia "de lo que es buenoy lo que es malo"14. Si lo tradujésemos a los problemas que nos interesan, habría que decir que el poder constituyente es un poder que se desenvuelve en un terreno moral desde el que se justifica un poder soberano que, como poder constituido, "oblig[a] a observar [las leyes de naturaleza], contrarias a nuestras pasiones naturales" 15 , para lo que dictará las leyes que ordenen la convivencia entre los hombres y establezcan lo justo e injusto. Pero Hobbes configura ese poder constituido como poder absoluto, sin límites, porque no sabe construirlo de otro modo, aunque la consecuencia de hacerlo así consiste en que ha de romper con su fundamento moral, por lo que terminará diseñándolo sólo y exclusivamente en términos fácticos, como el poder de una voluntad entendida empíricamente.

Hace falta precisar cómo ese proceso de institucionalización arriba a la construcción de un poder ilimitado. "Se dice que un Estado ha sido instituido, cuando una multitud de hombres establece un convenio entre todos y cada uno de sus miembros, según el cual se le da a un hombre o a una asamblea de hombres, por mayoría, el derecho de personificar a todos, es decir, de representarlos. Cada individuo de esa multitud, tanto el que haya votado a favor, como el que haya votado en contra, autorizará todas las acciones y juicios de ese hombre o asamblea de hombres, igual que si se tratara de los suyos propios, a fin de vivir pacíficamente en comunidad, y de encontrar protección contra otros hombres" ${ }^{\prime 16}$. Los hombres, pues aún no son súbditos, instituyen por mayoría una unidad, un pacto, un convenio, una persona que es el Estado que se encarna en el soberano. Es decir, "la persona del pueblo" ${ }^{17}$ es representada por el representante, el soberano. El único requisito que se ha de cumplir es que quienes entraron a debatir el pacto lo hicieran voluntariamente, pues "si entró voluntariamente en la congregación de quienes se reunieron para establecer el pacto, tácitamente dio su consentimiento para reconocer la voluntad de la mayoría"18. No interesa ahora precisar cuáles hayan de ser las condiciones en las que haya de expresarse esa voluntariedad a fin de que pueda considerarse como tal, ni tampoco las limitaciones a las que tuviera que someterse el ejercicio del principio de la mayoría, pues esos serán los problemas sobre los que se centrará la reflexión jurídico-política en los siglos siguientes. Sólo importa resaltar cómo se instituye una persona, el Estado, y cómo a partir de ahí se inicia una determinada manera de ordenar la convivencia. Son muchas las consecuencias que se derivan de esa institución. Entre ellas hay que resaltar especialmente tres de los derechos que posee aquel a quien se confiere el poder soberano y que se derivan de la institución del Estado: el derecho de establecer reglas, el derecho de judicatura y el de hacer la guerra y la paz, esto es, los poderes del estado que en el caso de Hobbes son los derechos de carácter indivisible que constituyen la esencia de la soberanía. Una soberanía que no puede estar limitada, pues quien la limitara sería, entonces, el soberano. Por eso, Hobbes afirmará que todo

\footnotetext{
${ }^{14}$ Hobbes, Leviatán, op. cit.pág. 132.

${ }^{15}$ Hobbes, Leviatán, op. cit.pág. 141.

${ }^{16}$ Hobbes, Leviatán, op. cit., pág. 146.

${ }^{17}$ Hobbes, Leviatán, op. cit., pág. 157.
} 
hombre ha de obedecer "tanto si formó parte de la congregación de votantes, como si no; ya se le consultase o no (...d)e lo contrario, será abandonado a su situación natural de guerra, como estaba antes, y podrá ser destruido por cualquier hombre sin que éste incurra en injusticia" ${ }^{19}$. Han de obedecer quienes consintieron voluntariamente, pero también quienes no formaron parte de la congregación de votantes, pues en el fondo las leyes naturales descubiertas "mediante la razón" ${ }^{20}$ - no tienen consistencia suficiente para imponerse en las relaciones humanas, pues estas leyes sólo "obligan in foro interno ${ }^{21}$, es decir, sólo apelan a un deseo de que se cumplan, pero no van más allá. Por tanto, una vez que se ha instituido la soberanía, ésta se independiza del terreno fáctico-moral, el estado de naturaleza, desde la que quedó constituida, y se concibe sólo en términos fácticos, con lo que no admite ningún tipo de límites.

La soberanía está, para Hobbes, "o en un hombre, o una asamblea de más de uno, asamblea en la que, o bien todo hombre tiene derecho a entrar, o bien únicamente ciertos individuos que se distinguen de los demás"22, por lo que sólo caben tres tipos de Estado: monarquía, aristocracia y democracia. Ahora es indiferente que Hobbes, prefiera, por diversas razones, la monarquía, frente a otras formas de Estado. Sin embargo, sí que hay que detenerse en lo que dice respecto a la cuestión de los límites del poder soberano, pues es aquí donde se muestra genuinamente su concepción del mismo. Dice: "un rey cuyo poder está limitado, no es superior a la persona o personas que tuvieron el poder de limitarlo; y quien no es superior, tampoco es supremo, es decir, que no es soberano"23, por lo que un monarca limitado no es soberano, "sino ministro de aquellos que tienen el poder soberano"24. Así pues, un poder soberano es instituido por el convenio establecido por el pueblo, y se define como poder absoluto sin posibilidad de límites. No importa que el poder soberano sea el de una asamblea o el de un monarca, sino que constitutivamente el poder soberano sea un poder ilimitado. "Y aunque de un poder tan ilimitado puedan -añadirá Hobbes- los hombres imaginar que se derivan muchas consecuencias malas, las consecuencias que se derivan de la falta de él, que es la guerra perpetua de cada hombre contra su vecino, son mucho peores. La condición humana en esta vida nunca estará libre de inconvenientes, pero en ningún estado hay inconveniencia más grande que la que procede de la desobediencia de los súbditos y del quebrantamiento de esos convenios en virtud de los cuales existe el Estado. Y quienquiera que, pensando que el poder soberano es demasiado grande, trate de reducirlo, tendrá en definitiva que someterse a otro poder que pueda limitar aquél, es decir, a un poder mayor"25.

\footnotetext{
${ }^{18}$ Hobbes, Leviatán, op. cit, págs. 148-149.

${ }^{19}$ Hobbes, Leviatán, op. cit., pág. 149.

${ }^{20}$ Hobbes, Leviatán, op. cit., pág. 110.

${ }^{21}$ Hobbes, Leviatán, op. cit., pág. 132.

${ }^{22}$ Hobbes, Leviatán, op. cit, pág. 155.

${ }^{23}$ Hobbes, Leviatán, op. cit., pág. 160.

${ }^{24}$ Hobbes, Leviatán, op. cit., pág. 160.

${ }^{25}$ Hobbes, Leviatán, op. cit., pág. 172.
} 
Ahora no es necesario reflexionar acerca de si su visión contractualista del orden social es acertada o desacertada, tampoco en su originario fundamento iusnaturalista, sino sólo sobre los términos en los que el poder soberano queda constituido como un poder absoluto y esto con independencia de que sea el poder de uno solo o de una asamblea. Para él, el poder soberano se constituye de manera ilimitada, en la medida en que renunciamos a nuestros derechos con la finalidad de que el poder que constituimos y al que hacemos esa entrega nos preserve en lo que más nos importa, la defensa de nuestra vida, pero incluso aunque vaya más allá, pues una vez que se ha constituido es un poder que escapa la posibilidad de su control, es un poder irrestricto. Con la finalidad de salir del estado de naturaleza constituimos un poder absoluto que todo lo puede sobre nosotros, en tanto que quedamos convertidos en sus súbditos. Una vez constituido nada cabe reclamar ni hacer a sus súbditos. Hemos creado un poder absoluto que por ser tal no cabe limitarlo sin que generemos un poder mayor que ese poder absoluto que tratamos de controlar. Se ha instituido un poder fáctico que sólo cabría limitar mediante un poder aún mayor, un poder que no puede ser ya el de un ser superior -veritas, en tanto que no admite la separación entre la religión y la política al defender la unidad política original, por lo que sólo podría constituir su límite el poder que proviniera de la auctoritas, aunque tampoco sería posible puesto que ésta no podría contraponerse a la potestas, ya que en Hobbes no es válida la distinción entre ambas, en tanto que la summa potestas ha sido transformada en summa auctoritas $^{26}$. De ahí que ese poder capaz de limitar el poder soberano sólo puede comprenderse como el poder de una voluntad aún más poderosa que la voluntad del poder que queremos limitar. Esta es la paradoja en la que Hobbes encierra al pensamiento jurídico-político al tratar de sacarnos de la situación de guerra permanente en que los hombres se encontraban en el estado de naturaleza, para introducirnos en un estado de guerra perpetua, pues sólo mediante el uso de una fuerza mayor que la que posee el poder establecido es como podremos derribarlo. A partir de ese momento, el pensamiento jurídico-político tratará de hacer dos cosas, primero limitarlo, aunque no tendrá demasiado éxito, pues los mecanismos con los que se intenta restringirlo pertenecen al pasado en la medida en que de lo que se trata es de una recuperación desnuda de los argumentos iusnaturalistas; después se intentará pensarlo de un modo distinto, como un ser de razón, esto es, normativamente y no fácticamente, con lo que se le podrá embridar sin caer ni en las insuficiencias de aquel iusnaturalismo ni en la paradoja hobbesiana, esto es, sin necesidad de generar un poder más absoluto que el propio poder absoluto que se trata de controlar.

\section{LA REVOLUCIÓN FRANCESA}

En el Leviatán, Hobbes había sostenido que sólo un poder más absoluto que el poder absoluto del soberano podría derribarlo, por lo que no encontraba razón en ello para demolerlo, pues si la razón para derribar el

\footnotetext{
${ }^{26}$ C. Schmitt, The Leviathan in the State Theory of Thomas Hobbes. Meaning and Failure of a Political Symbol, trad. G. Schwab y
} vol.11, no. 02, Rio de Janeiro, 2018. pp. 1087 - 1105 
poder absoluto consistía en la absolutez de ese poder, no tenía sentido defender la instauración de un poder que necesariamente habría de ser más absoluto que el propio poder absoluto que se trataba de sustituir. Esto es precisamente lo que sucederá en la revolución francesa. En ella, el poder absoluto del monarca es arrasado por el poder irrestricto del pueblo, cuya manifestación más preclara tuvo lugar en el terror. Todo el pensamiento filosófico-político posterior a esa revolución, desde las Reflections on the Revolution in France publicadas por E. Burke en 1790, estuvo presidido por lo que la misma conllevó. Cuenta Chateaubriand que "París no tenía, en 1792, la fisonomía de 1789 y 1790; no era la revolución naciente, era un pueblo que marchaba embriagado a su destino, a través de abismos, por sendas ignoradas. Sólo se veían por las calles figuras asustadas o feroces, gentes que se deslizaban a lo largo de las casas a fin de pasar inadvertidas, o que merodeaban buscando su presa; los primeros sin atreverse a miraros, los segundos clavando sus miradas duras en las vuestras para adivinaros y heriros [... Se sentía la aproximación de una joven tiranía plebeya, fecunda, es cierto, y llena de esperanzas, pero al par mucho más formidable que el despotismo caduco de la antigua monarquía: porque el pueblo soberano, como está en todas partes, cuando se convierte en tirano, está en todos los sitios; es la presencia universal de un Tiberio

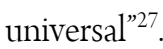

En ese mismo año, 1792, Marat y Danton organizaron con ayuda de los marselleses que arribaron a París en agosto las matanzas de septiembre. El 21 de enero de 1793, Luis XVI fue guillotinado. En abril, se creó el Comité de Salvación Pública, encabezado por Robespierre, con la finalidad de apoyar al Comité de Seguridad General, creado en 1792. El cinco de septiembre, la Convención aprobó medidas de terror para reprimir las actividades contrarrevolucionarias. El terror duró hasta la primavera de 1794, aunque en realidad había quedado instaurado desde los comienzos de la propia Revolución. El mismo Chateaubriand relata que en julio de 1789 encontrándose en el balcón de su posada, próxima a las Tullerías, pudo contemplar a lo lejos una muchedumbre que gritando a favor de la libertad se encaminaba hacia donde él se encontraba. Al acercarse pudo ver a unos descamisados, que llevaban por estandartes unas picas con dos cabezas en sus puntas. Afirma, aunque dada la situación sea difícilmente creíble, que les increpó diciéndoles: “¡Miserables! [...] ¿ies así como entendéis la libertad?"28.

Parece ser que la revolución francesa causó, en sus inicios, una admiración enorme, aunque en muy poco tiempo se produjo una reacción adversa por el inmenso temor que provocó. No hace falta sino recordar el terrible juicio que formuló Hegel sobre Robespierre, al considerar que el principio que defendía -"para mantener la virtud

\footnotetext{
E. Hilfstein, Greenwood Press, London, 1996 (1938), págs. 44-45.

${ }^{27}$ Chateaubriand, Memorias de ultratumba, sel. y pról. de A. Ramoneda, trad. de J. Zamacois, Alianza, Madrid, 2003 (1848-1850), págs. 214-215.

${ }^{28}$ Chateaubriand, Memorias ..., op. cit., pág. 168.
} 
es necesario el terror"-, "era también el principio de los mahometanos"29, quienes habían roto con todos los particularismos, pues para ellos sólo "lo uno, lo absoluto, es conocido $[\ldots y$ c $]$ onocer este uno y adorarlo es $[\ldots]$ un deber $[\ldots]$ En cuanto que este uno es lo único que vale y es realizado, dedúcese la destrucción de todas las diferencias; y esto constituye el fanatismo"30. En Robespierre, el principio será "libertad y terror", como en el mahometanismo "[r] eligión y terror" ${ }^{\text {”1 }}$.

Para Hegel, el trasfondo de la revolución francesa radica en que en ella la libertad absoluta es incapaz de determinarse excepto por medio del terror, es decir, mediante la aniquilación de toda diferencia, de todo particularismo. La razón se encuentra en que como "ninguna obra ni acto positivos puede producir la libertad universal; a dicha libertad sólo le resta el obrar negativo; es solamente la furia del desaparecer" ${ }^{\text {"32 }}$. La libertad absoluta lleva en sí la negación y se muestra como lo negativo para la conciencia singular. Esto conduce a que las conciencias individuales temerosas de la muerte retornen a una obra dividida y limitada. La autoconciencia ha experimentado la fuerza contra ella negativa de su esencia universal. Dentro de la libertad absoluta no estaban en interacción mutua ni la conciencia, inmersa en la multiplicidad de la existencia, ni tampoco un mundo exterior válido, sino que lo estaban el mundo en la forma de la conciencia como voluntad universal y la autoconciencia replegada de toda existencia en el simple sí mismo. Aquí, la pura y simple realidad de la cultura desaparece y se trueca en la nada vacía. Toda determinación se ha perdido "en la pérdida que el sí mismo experimenta en la libertad absoluta; su negación es la muerte carente de significación, el puro terror de lo negativo, que no lleva en él nada positivo, nada que lo cumpla”33.

Ahora bien, la libertad absoluta pasa de la realidad que se destruye a sí misma a otra región del espíritu autoconsciente, a la moralidad, al espíritu cierto de sí mismo o espíritu subjetivo. La unidad inmediata de la conciencia con la voluntad universal hace que para la conciencia desaparezca el ser abstracto, esto es, la voluntad universal. La conciencia sabe la voluntad pura como sí misma y se sabe como esencia, es decir, la conciencia es voluntad universal como este puro saber y querer y "el puro saber como esencia es la voluntad universal" ${ }^{4}$. Pero Hegel defenderá la necesidad de abandonar el mero punto de vista moral para pasar al concepto de la eticidad, pues si no lo hiciéramos, el mérito de la crítica moral quedaría convertido "en un vacío formalismo y la ciencia moral en una retórica acerca del deber por el deber mismo"35.

Por eso trató de lograr la realización efectiva de la idea ética, la idea de la libertad, a través de la

\footnotetext{
${ }^{29}$ G. W. F. Hegel, Lecciones sobre la filosofia de la historia universal, pról. de J. Ortega y Gasset, adv. y trad. de J. Gaos (1928), Alianza, Madrid, 1980 (1830), pág. 596.

${ }^{30}$ Hegel, Lecciones ..., op. cit., pág. 591.

${ }^{31}$ Hegel, Lecciones ..., op. cit., pág. 593.

${ }^{32}$ G. W. F. Hegel, Fenomenología del Espíritu, trad. de W. Roces, Fondo de Cultura Económica, México, 1966 (1807), pág. 346.

${ }^{33}$ Hegel, Fenomenología ..., op. cit., pág. 349.

${ }^{34}$ Hegel, Fenomenología ..., op. cit., pág. 350.

${ }^{35}$ G. W. F. Hegel, Principios de la Filosofia del Derecho, trad. de J. L. Vermal, Edhasa, Barcelona, 1988 (1821), \$ 135, pág. 198.
} 
institucionalización de un Estado, que no podía dejar al albur de las necesidades y los intereses arbitrarios de las diferentes voluntades particulares, sin que por ello esas necesidades e intereses particulares quedaran desatendidos, ya que todo su sistema se construye sobre el papel central que juegan ambos, el interés general y los intereses particulares, aunque lo haga de modo tal que la autoconciencia particular ha de elevarse a su universalidad, de manera que aquélla quede mediada con ésta. Esto lo logrará con la creación de una constitución racional, en la que se reconozcan las instituciones necesarias a través de las cuales se asegure esa mediación entre necesidades e intereses particulares y el interés general, con el fin de que la autoconciencia particular alcance su universalidad.

En definitiva, Hegel se ocupó de la construcción de un Estado racional ${ }^{36}$ al tratar de solventar el problema de la voluntad general de una manera científica, esto es, al alojar las necesidades e intereses particulares en las esferas de la familia y la sociedad civil de manera que se asegurase su mediación con el interés universal, al mismo tiempo que su supeditación al mismo, en las instituciones del Estado. De esta manera, toda su construcción estaba dirigida a impedir que cayéramos por el precipicio de una voluntad subjetiva arbitraria y caprichosa ${ }^{37}$, lo que constituye precisamente el riesgo de nuestras democracias ${ }^{38}$.

Aunque no posea la profundidad del segundo ni se adorne con los detalles del primero, hay que reconocer que el pensamiento político de Schiller también estuvo presidido por los efectos derivados de la revolución. Escribió sus Cartas entre los años 1793 y 1795, en pleno auge del terror. Por eso lo tendrá muy presente en las siete primeras Cartas, donde trata de elaborar una teoría sobre el Estado. Schiller reconoce las ventajas de esa revolución, pero también sus inconvenientes. En relación con las primeras sabe que gracias a ella se ha desenmascarado la arbitrariedad, una arbitrariedad que no puede "aparentar ya la más mínima dignidad"39, por lo que "el hombre ha despertado de su larga indolencia y del engaño en que complacía, y [en consecuencia] exige insistentemente la restitución de sus derechos inalienables" ${ }^{\prime 40}$. Con respecto a los segundos subraya sus excesos en tanto que propició la disolución del orden social. Su juicio negativo se vierte, en primer lugar, sobre las clases bajas, en las que advierte "impulsos primitivos y sin ley que, una vez deshechos los lazos del orden social, se desencadenan y apresuran con furia indomable a satisfacer sus impulsos animales"41. Por eso las calificará en su

\footnotetext{
${ }^{36}$ A pesar de que Hegel era consciente de la dificultad de tal tarea -"si es difícil concebir la naturaleza, es infinitamente más duro aprehender el estado"-, defenderá la necesidad de construir una ciencia del estado, que "no debe ser otra cosa que el intento de concebir y exponer el estado como algo en sí mismo racional', vid., Principios..., op. cit., agreg., par. 272, pág. 352 y prefacio, págs. 5152 , respectivamente.

${ }^{37}$ Hegel se había referido los enfrentamientos que podrían producirse entre sucesivas mayorías, problema que, en su opinión, es el que "la historia ha de resolver en los tiempos venideros", en Hegel, Lecciones ..., op. cit., p. 697.

${ }^{38}$ Vid., al respecto, José J. Jiménez Sánchez, “Una comprensión monstruosa del derecho a decidir”, ms., 2016.

${ }^{39}$ Schiller, Cartas ..., op. cit., pág. 137.

${ }^{40}$ Schiller, Cartas ..., op. cit., pág. 137.

${ }^{41}$ Schiller, Cartas ..., op. cit., pág. 137.
} 
exceso como locos [Rasender $\left.{ }^{42}\right]$. Distingue tres clases de hombres, el salvaje, el bárbaro y el hombre culto. La oposición fundamental es la que establece entre el primero y el tercero, sobre la que construirá el paso del Estado natural al Estado moral, aunque su juicio sobre el segundo, el hombre bárbaro, constituya una crítica radical a la propia revolución, pues el hombre revolucionario impone sus principios aun a costa de la destrucción de su propia naturaleza. El "hombre puede oponerse a sí mismo de dos maneras: o bien como salvaje, si sus sentimientos dominan a sus principios; o bien como bárbaro, si sus principios destruyen a sus sentimientos. El salvaje desprecia la cultura y considera la naturaleza como su señor absoluto; el bárbaro se burla de la naturaleza y la difama, pero es más despreciable que el salvaje, porque sigue siendo en muchos casos el esclavo de su esclavo. El hombre culto se conduce amistosamente con la naturaleza: honra su libertad, conteniendo simplemente su arbitrariedad”43. Esta es la razón por la que su exigencia respecto de las clases cultas [die civilisirten Klassen ${ }^{44}$ ] sea enorme, al mismo tiempo que su juicio sobre ellas sea terrible cuando no cumplen con su cometido, por lo que llegará a decir de las mismas que nos ofrecen una "imagen todavía más repulsiva de una postración y de una depravación de carácter que indigna tanto más cuanto que la cultura misma es su fuente" ${ }^{m 5}$. Su juicio es demoledor, pues las tacha de indignas [Nichtswürdiger $\left.{ }^{46}\right]$.

Frente a esta situación de desorden y caos generada por la revolución, Schiller defenderá la necesidad del Estado, del que dice que su disolución contiene precisamente su justificación ["Seine Auflösung enthält seine Rechtfertigung" ${ }^{\text {"7 }}$, pues una vez que en la sociedad se han desatado "los lazos que la fundamentan [la sociedad desatada, die losgebundene Gesellschaft], en lugar de progresar hacia una vida orgánica [en lugar de apresurarse hacia la vida orgánica, anstatt aufwärts in das organische Leben zu eilen], se precipita de nuevo en el reino de las fuerzas elementales [en el reino de lo elemental, in das Elementarreich]"48. Ahora bien, el modelo de Estado que defiende Schiller no tiene nada que ver con los que se propusieron por parte de Hobbes o los revolucionarios franceses. Su Estado es un Estado moral, concebido normativamente y no fácticamente.

\section{LA CONSTRUCCIÓN DE UN ESTADO MORAL}

La dificultad radica en cómo construir el Estado en tanto que vida orgánica superior, teniendo en cuenta que vivimos en una nueva época. Schiller dice que somos modernos $\left[\mathrm{Neuern}^{49}\right]$ frente a los griegos, para quienes los elementos de la naturaleza humana no quedaban desmembrados, sino combinados de forma que todos

\footnotetext{
${ }^{42}$ Schiller, Cartas ..., op. cit., pág. 138.

${ }^{43}$ Schiller, Cartas ..., op. cit., pág. 135.

${ }^{44}$ Schiller, Cartas ..., op. cit., pág. 138.

${ }^{45}$ Schiller, Cartas ..., op. cit., pág. 139.

${ }^{46}$ Schiller, Cartas ..., op. cit., pág. 138.

${ }^{47}$ Schiller, Cartas ..., op. cit., pág. 138.

${ }^{48}$ Schiller, Cartas ..., op. cit., pág. 139.
} 
disfrutaban de una completa humanidad. Sin embargo, la imagen de la especie se ha proyectado en nosotros de modo distinto, al hacerlo "en fragmentos aislados sin posible combinación, de manera que hemos de indagar individuo por individuo para componer la totalidad de la especie [die Totalität der Gattung]"50. Esto conlleva que el hombre moderno, al contrario que el griego, no pueda erigirse en representante de su tiempo. La justificación la encuentra en que al griego le dio forma la naturaleza, "que todo lo une"51, mientras que al moderno se la da el entendimiento [der Verstand], "que todo lo divide" ${ }^{2}$. En definitiva, es la propia cultura la que propició el desgarramiento de "la unidad interna de la naturaleza humana"53. De ahí que Schiller trate de evitar el desmembramiento y descomposición que conlleva la preeminencia de los intereses particulares recuperando el interés de la especie, lo que únicamente puede alcanzarse por medio de la razón [die Vernunft]. Schiller resume su planteamiento de la siguiente manera:

"El filósofo y el hombre de mundo dirigen expectantes su mirada hacia la escena política [auf den politischen Schauplatz], donde en estos momentos, según parece, se está decidiendo el gran destino de la humanidad [...] Una cuestión que hasta ahora sólo había dilucidado la ciega ley del más fuerte [das blinde Recht des Stärken], se ha llevado, según parece, ante los tribunales de la razón pura [ante el tribunal, vor dem Richterstuhle reiner Vernunft], y aquel que sea capaz de llegar al punto central de la cuestión [al centro del todo] y elevarse desde su individualidad a la universalidad de la especie [especie] [und wer nur immer fähig ist, sich in das Centrum des Ganzen zu verstehen, und sein Individuum zur Gattung zu steigern], puede considerarse miembro de este tribunal de la razón, del mismo modo que, en cuanto hombre y ciudadano universal [als Mensch und Weltbürger], es parte interesada en el asunto y se ve envuelto de uno u otro modo en su solución. Así pues, lo que se decide en este juicio no es sólo un asunto particular, sino que la sentencia debe pronunciarse según leyes [nach Gesetzen] que cada hombre, en cuanto espíritu racional [als vernünftiger Geist], está capacitado y autorizado para dictar ${ }^{n 4}$.

Se trata, pues, de salir del Estado de naturaleza, en el que predomina el derecho del más fuerte para entrar en un Estado de leyes, que todo hombre en tanto que espíritu racional puede darse, es decir, que todo hombre en tanto que tal y como ciudadano del mundo será miembro del tribunal que dictará esas leyes, si es capaz de situarse en el centro del todo y abandonar sus intereses particulares por los de la especie. Dicho de otro modo, los hombres decidirán en tanto que seres racionales en función de lo que importa a la especie y no a su individualidad. Esto es lo que implica su racionalidad y, en consecuencia, su pertenencia al tribunal de la razón pura. Sólo así estarán capacitados para alcanzar "los principios generales [los principios, die Grundsätze] por los que se guía la razón para llevar a cabo una legislación política [bey einer politischen Gesetzgebung]”55.

\footnotetext{
${ }^{49}$ Schiller, Cartas ..., op. cit., pág. 144.

${ }^{50}$ Schiller, Cartas ..., op. cit., pág. 145.

${ }^{51}$ Schiller, Cartas ..., op. cit., pág. 145.

${ }^{52}$ Schiller, Cartas ..., op. cit., pág. 145.

${ }^{53}$ Schiller, Cartas ..., op. cit., pág. 147.

${ }^{54}$ Schiller, Cartas ..., op. cit., pág. 119.

${ }^{55}$ Schiller, Cartas ..., op. cit., pág. 121.
} 
Para explicarlo, Schiller parte de un estado natural [Naturstand], una situación creada por la pura naturaleza sujeta a la mera necesidad, en la que reina un "feroz libertinaje [die wilde Ungebundenheit]"56. El hombre no tiene ninguna experiencia de este estado natural, pero le da forma en el mundo de las ideas, lo que "le viene impuesto necesariamente por su determinación racional [durch seine Vernunftbestimmung]", otorgándole "a ese estado ideal [in diesem idealischen Stand] una finalidad que no tenía el auténtico estado natural [in seinem wirklichen Naturstand], y se da a sí mismo un derecho de elección del que entonces no era capaz. Actúa como si comenzara desde el principio, y como si valiéndose de un discernimiento claro [aus heller Einsicht] y decidiéndolo libremente, cambiara el estado de independencia [Stand der Unabhängigkeit] por el estado contractual [Stand der Verträge]"57.

Así, el hombre "[d]espierta del letargo de la vida sensible, se reconoce como hombre $[\ldots]$ y se encuentra ... en el Estado [in dem Staate]. La coacción de las necesidades le precipitó en él antes de que pudiera elegirlo libremente; la necesidad lo implantó con arreglo a leyes puramente naturales [nach blossen Naturgesetzen], antes de que élpudiera implantarlo conforme a las leyes de la razón [nach Vernunftgesetzen]. Pero, en cuanto persona moral [moralische], el hombre no podía, ni podrá nunca conformarse con ese Estado de necesidad [Nothstaat] que había surgido sólo y exclusivamente de su determinación natural”58. El problema para Schiller no es que el hombre haya pasado del letargo de la vida sensible a una vida en el Estado, sino que ese Estado sea un Estado impuesto por la necesidad natural y, por consiguiente, no elegido libremente. Es decir, el hombre ha pasado del estado natural al Estado de naturaleza sin que tal paso haya sido mediado por su libertad, por lo que ha sido la mera necesidad, las fuerzas de la naturaleza, las que lo han conducido a esta nueva situación, que consiste en un Estado de necesidad sometido a las leyes naturales. En este Estado natural habita el hombre físico [der physische Mensch ${ }^{59}$ ] que es real [ wirklich $^{60}$, pero no vive, por tanto, el hombre moral [moralisch, sittlich ${ }^{61}$, que se caracteriza por su problematicidad ${ }^{62}$, esto es, por su libertad. Por eso, el "Estado natural (como puede denominarse a todo cuerpo político [jeder politische Körper] que deriva originariamente su organización [fundación, Einrichtung] a partir de fuerzas naturales [Kräften] y no de leyes [Gesetzen]) se opone al hombre moral [moralischen], cuya única ley es, precisamente, la adecuación a las leyes [die blosse Gesetzmässigkeit zum Gesetz], y es en cambio suficiente para el hombre físico, que se da a sí mismo leyes únicamente para adaptarse a

\footnotetext{
${ }^{56}$ Schiller, Cartas ..., op. cit., pág. 163.

${ }^{57}$ Schiller, Cartas ..., op. cit., pág. 123.

${ }^{58}$ Schiller, Cartas ..., op. cit., págs. 121-123.

${ }^{59}$ Schiller, Cartas ..., op. cit., pág. 124.

${ }^{60}$ Schiller, Cartas ..., op. cit., pág. 124.

${ }^{61}$ Schiller, Cartas ..., op. cit., pág. 124. Schiller utiliza ambos términos de manera indistinta. A veces usa también y en el mismo sentido el adjetivo ethisch, vid., id., pág. 160.

${ }^{62}$ El hombre moral [sittliche] es problemático [problematisch], dirá Schiller, Cartas ..., op. cit., pág. 124.
} 
esas fuerzas" 63 .

No obstante, el hombre "no permanece en el estado [er bey dem nicht stille steht] en que lo dejó la pura naturaleza, sino que posee la facultad de rehacer por medio de la razón [durch Vernunft] el camino que ya había recorrido antes con la naturaleza, la facultad de transformar [umschaffen] la obra de la mera necesidad en obra de su libre elección [seiner freyen Wahl] y de elevar la necesidad física a necesidad moral [moralischen Nothwendigkeit $]^{\prime 64}$. Se trata por tanto de arrumbar el Estado de naturaleza y su necesidad impuesta por aquellas fuerzas naturales que nos exigen determinados comportamientos para asegurar nuestra pervivencia. Frente a ello habría que "sentar en el trono a la ley [das Gesetz], de honrar por fin al hombre como fin en sí, y hacer de la verdadera libertad el fundamento de la unión política [der politischen Verbindung] [ ... Aunque para lograrlo falte aún] la posibilidad moral[die moralische Möglichkeit]”65.

En definitiva, ese Estado natural se asienta sobre la arbitrariedad [die blinde Willkühr ${ }^{66}$, que naturalmente es ciega, esto es, sin que se atenga a una finalidad trazada de manera racional. De ahí que si bien puede imponerse por la fuerza natural, no tiene, sin embargo, ninguna autoridad para someter nuestra libertad, porque "la obra de las fuerzas ciegas [das Werk blinder Kräfte] no posee ninguna autoridad ante la cual la libertad haya de doblegarse, y todo ha de conformarse a la finalidad suprema que la razón [Vernunft] asienta en la personalidad del hombre. Así nace y se justifica el intento de una nación adulta [eines mündig gewordenen Volks] de transformar su Estado natural [Naturstaat] en un Estado moral [in einen sittilchen]"67. Este Estado moral es el Estado de la libertad política, un Estado libremente elegido y presidido por leyes de razón que se asientan sobre el carácter de una nación $[\mathrm{Volk}]$, aunque de manera que se mantenga una tensión entre razón y naturaleza. Esto es, se trata de librarnos del yugo de la naturaleza, pero sin que ésta quede destruida, pues si así ocurriera, seríamos nosotros los que nos destruiríamos. De ahí que haya de lograrse la articulación entre ambas, entre naturaleza y razón.

El Estado tiene que fundarse tal como la razón lo concibe en la idea ["der Staat, wie ihn die Vernunft in der Idee sich aufgiebt ... musste selbst erst darauf gegründet werden" $\left.{ }^{n 8}\right]$, aunque esto no sea suficiente, pues es necesario que "la naturaleza humana $[\ldots]$ se desarrolle lo suficiente como para ser ella misma la artífice y garantizar la realidad de la creación política de la razón [der politischen Schöpfung der Vernunft]”ø9. Así pues, la razón le quita al hombre los medios de su animalidad, que es condición de su humanidad, es decir, le arrebata "algo

\footnotetext{
${ }^{63}$ Schiller, Cartas ..., op. cit., pág. 125.

${ }^{64}$ Schiller, Cartas ..., op. cit., pág. 121.

${ }^{65}$ Schiller, Cartas ..., op. cit., pág. 137.

${ }^{66}$ Schiller, Cartas ..., op. cit., pág. 122.

${ }^{67}$ Schiller, Cartas ..., op. cit., págs.. 123-124.

${ }^{68}$ Schiller, Cartas ..., op. cit., pág. 160.

${ }^{69}$ Schiller, Cartas ..., op. cit., pág. 161.
} 
que es propiamente suyo"70, al mismo tiempo que lo instruye en algo [und weist ihn dafür an etwas $\mathrm{an}^{71}$ ] "que

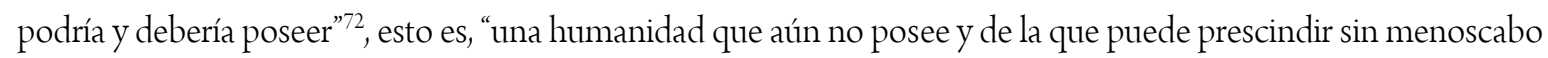
de su existencia [und unbeschadet seiner Existenz mangeln kann]”73. Por eso, "la razón suprime el Estado natural [... ] para establecer el suyo en su lugar, [con lo que] arriesga al hombre físico y real en pro del supuesto y moral [problemático y ético, problematischen sittlichen], arriesga la existencia [Existenz] de la sociedad en pro de un ideal de sociedad meramente posible (aunque moralmente necesario [moralisch nothwendiges]) ${ }^{p 74}$. Pero no hasta el punto de negar la existencia de tal tensión entre naturaleza y razón, necesidad y libertad, unidad moral $\left[\right.$ moralische Einheit ${ }^{75}$ y variedad de la naturaleza [die Mannichfaltigkeit der Natur ${ }^{76}$. Por el contrario, Schiller defiende ambas a la vez, aunque reconozca que la dificultad se encuentra en cómo impedir que la unidad moral se imponga sobre la variedad de la naturaleza, así como que ésta disuelva a aquélla. De ahí que sostenga que la primera "en la sociedad física, no debe dañar por ello la variedad de la naturaleza [ . . . así como que] si la naturaleza aspira a afirmar su multiplicidad en la estructura moral [in dem moralischen Bau] de la sociedad, no debe hacerlo en detrimento de la unidad moral; la victoriosa forma se halla a igual distancia de la uniformidad [Einförmigkeit] que del desorden [confusión, Verwirrung]" 77 . Se trataría, por tanto, de ser capaces de transformar el Estado de necesidad [Staat der $\mathrm{Noth}^{78}$ ] en un Estado de libertad [Staat der Freyheit ${ }^{79}$, de manera que se asegurara en éste la variedad de la naturaleza, lo que sólo puede alcanzarse cuando ésta se somete a la unidad del ideal, en la que "el sometimiento a formas ajenas y despóticas debe haber dejado paso a una aceptable libertad [einer anständigen Freyheit]"

Una libertad que sólo puede desarrollarse cuando se haya abandonado la arbitrariedad y construido una verdadera libertad política. Por eso sostiene que mientras que "el hombre natural [der Naturmensch] siga haciendo un uso tan anárquico de su albedrío [arbitrariedad, Willkühr], apenas puede mostrársele su libertad"81, para lo que es preciso que se reconduzca la naturaleza antes de que se reconozcan los principios liberales, pues en caso contrario, esos mismos principios terminarían por reforzar "una naturaleza ya de por sí demasiado poderosa" ${ }^{\$ 2}$. No obstante, Schiller terminará por resolver la tensión entre naturaleza y razón mediante la

\footnotetext{
${ }^{70}$ Schiller, Cartas ..., op. cit, pág. 125.

${ }^{71}$ Schiller, Cartas ..., op. cit., pág. 124.

${ }^{72}$ Schiller, Cartas ..., op. cit, pág. 125.

${ }^{73}$ Schiller, Cartas ..., op. cit, pág. 125.

${ }^{74}$ Schiller, Cartas ..., op. cit., pág. 125.

${ }^{75}$ Schiller, Cartas ..., op. cit., pág. 134.

${ }^{76}$ Schiller, Cartas ..., op. cit., pág. 134.

${ }^{77}$ Schiller, Cartas ..., op. cit., pág. 135.

${ }^{78}$ Schiller, Cartas ..., op. cit., pág. 134.

${ }^{79}$ Schiller, Cartas ..., op. cit., pág. 134.

${ }^{80}$ Schiller, Cartas ..., op. cit., págs. 161-163.

${ }^{81}$ Schiller, Cartas ..., op. cit., pág. 163.

${ }^{82}$ Schiller, Cartas ..., op. cit., pág. 163.
} 
imposición de la ley de la razón, puesto que "la razón sólo se da por satisfecha si su ley se impone sin condiciones ${ }^{\prime 33}$. Sin embargo, esto no le impide subrayar que si bien la

"razón exige unidad [Einheit], [...] la naturaleza exige variedad [Mannichfaltigkeit], y el hombre es reclamado por ambas legislaciones. Una conciencia incorruptible le ha inculcado la ley de la razón, y la ley natural le viene dada por un sentimiento indestructible. Por tanto, en el caso de que el carácter moral [sittliche] sólo pueda afirmarse mediante el sacrificio del carácter natural, se evidenciará entonces un grado de formación aún deficiente, y una constitución política [Staatsverfassung] que sólo sea capaz de llevar a cabo la unidad [Einheit] suprimiendo la variedad [Mannichfaltigkeit] será aún muy imperfecta. El Estado [der Staat] no puede honrar sólo el carácter objetivo y genérico de los individuos, sino que ha de honrar también su carácter subjetivo y específico; y ha de procurar no despoblar el reino de los fenómenos por ampliar el invisible reino de la moral [das unsichtbare Reich der Sitten $]^{384}$.

Ahora bien, sólo será posible la construcción de ese Estado moral si el carácter dominante de una nación [Volk] constituye un tercer carácter afín al físico y al moral, pues ni uno ni el otro son suficientes. Primero, porque el carácter natural del hombre es egoísta y violento, por lo que tiende a la destrucción de la sociedad y, segundo, porque el carácter moral presenta otros inconvenientes: primero porque el legislador no puede basarse en este carácter en la medida en que no esté aún formado y, segundo, porque cuando lo está, "el legislador no podría basarse ni confiar plenamente, porque es libre y porque nunca se manifiesta como fenómeno" ${ }^{85}$. Dicho en otros términos, esta tensión es la que también se produce entre el espíritu especulativo y el espíritu práctico [der Geschäftsgeist], dado que el primero tiende hacia la abstracción, olvidándose de lo singular, y el segundo pierde, por el contrario, la posibilidad del todo por su preocupación por lo concreto ["jener für das Einzelne zu hoch, dieser zu tief für das Ganze stand"86]. La solución de Schiller consistirá en "separar del carácter físico la arbitrariedad [die Willkühr] y del carácter moral la libertad, de hacer concordar el primero con las leyes y de hacer que el segundo dependa de las impresiones - de alejar un poco a aquél de la materia y acercársela a éste un poco más ... y todo ello para crear un tercer carácter que $[\ldots]$ haga posible el tránsito desde el dominio de las fuerzas naturales al dominio de las leyes y que, sin poner trabas al desarrollo del carácter moral, sea más bien la garantía sensible de esa invisible moralidad" ${ }^{87}$. En definitiva se trataría de "alejarse al principio de la naturaleza", para "ser capaces de regresar a ella por medio de la razón" ${ }^{8}$, al modo en que la naturaleza griega "se alió con todos los encantos del arte y con toda la dignidad de la sabiduría, sin convertirse por ello, como nosotros, en su víctima"s9, con lo que evitaríamos que se produzca la desnaturalización de nuestras costumbres.

\footnotetext{
${ }^{83}$ Schiller, Cartas ..., op. cit., pág. 131.

${ }^{84}$ Schiller, Cartas ..., op. cit., pág. 131.

${ }^{85}$ Schiller, Cartas ..., op. cit., pág. 127.

${ }^{86}$ Schiller, Cartas ..., op. cit., pág. 151.

${ }^{87}$ Schiller, Cartas ..., op. cit., pág. 127.

${ }^{88}$ Schiller, Cartas ..., op. cit., pág. 143.

${ }^{89}$ Schiller, Cartas ..., op. cit., pág. 143.
} 


\section{CONCLUSIÓN}

De acuerdo con Schiller, "sólo en el ser absoluto la necesidad física coincide con la necesidad moral"90, mientras que en el ser humano, las determinaciones de la voluntad "son siempre arbitrarias [zufällig bleiben]" por lo que

"para considerar el comportamiento moral del hombre como una consecuencia natural, es necesario que ese comportamiento sea natural, y que el hombre sea inducido ya por sus propios impulsos a conducirse moralmente. Pero la voluntad del hombre [der Wille des Menschen] oscila con entera libertad entre el deber y la inclinación, y ninguna coacción física puede ni debe inmiscuirse en ese derecho soberano de su persona. Así pues, si el hombre quiere conservar esa capacidad de elección, sin dejar de ser por ello un eslabón seguro en el encadenamiento causal de las fuerzas naturales, es necesario que los efectos de aquellos dos impulsos coincidan plenamente en el reino de los fenómenos y que, a pesar de su extrema diferencia formal, la materia de su voluntad continúe siendo la misma; es decir, que los impulsos del hombre coincidan lo suficiente con su razón [Vernunft], como para hacer posible una legislación universal [universelle Gesetzgebung]"92.

Lo había explicado al comienzo cuando sostuvo que la sensibilidad es la que le proporcionará los hechos y la libre fuerza de pensamiento la que dictará las leyes ${ }^{93}$. Aunque lo dirá de manera más sencilla cuando apoyándose en Fichte defienda que cada hombre particular [der individuelle Mensch ${ }^{94}$, temporal [der Mensch in der Zeit ${ }^{95}$ ], lleva en sí un hombre puro [der reine Mensch ${ }^{96}$, ideal [der Mensch in der Idee ${ }^{97}$, con el que ha de estar en armonía, y esto se logra precisamente en el Estado:

"A este hombre puro, que se da a conocer con mayor o menor claridad en todo sujeto, lo representa el Estado, que es la forma objetiva y, por así decir, canónica, en la que trata de unirse la multiplicidad de los sujetos. Ahora bien, el hombre temporal y el hombre ideal pueden llegar a coincidir de dos maneras distintas, las mismas por las que el Estado se afirma en los individuos: o bien el hombre puro somete al empírico, es decir, el Estado suprime a los individuos; o bien el individuo se convierte en Estado, es decir, el hombre temporal se ennoblece convirtiéndose en hombre ideal" ${ }^{\prime \prime}$.

Ahora bien, este juego que Schiller plantea entre lo temporal y lo ideal, entre individuo y Estado, no es admisible desde una perspectiva exclusivamente moral, pues la razón ha de imponer su ley, aunque sí lo sea desde el punto de vista del hombre, para el que no sólo cuenta la forma, sino también el contenido, la materia, puesto que el hombre no puede renunciar a las sensaciones, a los sentimientos [die lebendige Empfindung ${ }^{99}$. No obstante,

\footnotetext{
${ }^{90}$ Schiller, Cartas ..., op. cit., pág. 129.

${ }^{91}$ Schiller, Cartas ..., op. cit, pág. 129.

92 Schiller, Cartas ..., op. cit., pág. 129.

93 "Vuestra libertad de espíritu será siempre algo inviolable para mí. Vuestra propia sensibilidad me proporcionará los hechos que han de servir de fundamento a mi teoría, vuestro entendimiento [Denkkraft] libre dictará las leyes según las que habré de proceder”, en Schiller, Cartas ..., op. cit., pág. 113.

${ }^{94}$ Schiller, Cartas ..., op. cit., pág. 128.

${ }^{95}$ Schiller, Cartas ..., op. cit., pág. 130.

${ }^{96}$ Schiller, Cartas ..., op. cit., pág. 130.

${ }^{97}$ Schiller, Cartas ..., op. cit., pág. 130.

${ }^{98}$ Schiller, Cartas ..., op. cit., págs. 129-131.

${ }^{99}$ Schiller, Cartas ..., op. cit., pág. 130.
} 
ese juego es mucho más complejo de lo que en principio podríamos suponer, ya que "mientras la sociedad moral se forma en la idea, la sociedad física no puede detenerse en el tiempo ni por un momento, no puede poner en peligro su existencia en pro de la dignidad humana"100. Schiller sabe que la construcción del Estado moral es un intento de asegurar una convivencia racional entre los seres humanos, aunque es consciente de que, al final, "la gran soberana [die grosse Beherrscherin] de todos los asuntos humanos, [es] la fuerza ciega [die blinde Stärke]”101, que es la que puede terminar por intervenir y resolver los conflictos de principio. A pesar de ello, Schiller defenderá la necesidad del artista político y pedagogo [der pädagogische und politische Künstler], que hace del hombre su materia y su tarea al mismo tiempo [... El político [der Staatskünstler] ha de acercarse a su materia con un respeto muy distinto al que demuestra el artista [der schöne Künstler], no de manera subjetiva, ni provocando un efecto engañoso para los sentidos, sino de manera objetiva $[\ldots]$ porque el Estado ha de ser una organización [Organisation] que se forma por y para sí misma, sólo puede hacerse real [wirklich] si las partes han coincidido en la idea del todo. Dado que el Estado representa a la humanidad pura y objetiva en el corazón de sus ciudadanos, tiene que observar hacia ellos la misma relación que ellos mantienen consigo mismos, y honrar así su humanidad subjetiva sólo en el grado en que ésta se ennoblece haciéndose objetiva"102.

Pero esto no puede llevarnos a pensar ese Estado como un ente absoluto que aplaste toda diferencia, porque se es "tanto ciudadano de una época como de un Estado"103, es decir, ese Estado ha de enmarcarse necesariamente en los usos y costumbres del espacio y tiempo en que se vive, al mismo tiempo que se ha de mantener la singularidad del hombre, "aun en el caso de que adecue sus actos a la regla de conducta más universal"104, siendo el Estado "el mero intérprete de su bello instinto, [ ... ] tan sólo una fórmula más clara de su legislación interior" ${ }^{105}$. Por eso, el Estado no puede quedar reducido a un mecanismo vulgar, "en el cual la existencia mecánica del todo se forma a partir de la concatenación de un número infinito de partes, que carecen de vida propia" ${ }^{106}$. Si así ocurriera, se aniquilaría la vida de los individuos, "para que el todo absoluto [das Abstrakt des Ganzen] siga manteniendo su miserable existencia” ${ }^{107}$. Por el contrario, el Estado no puede ser ajeno a sus ciudadanos, en tanto que no lo es a sus sentimientos, sino que ha de aspirar a una vida orgánica superior, aunque "si en el carácter de una nación el hombre subjetivo se contrap[usiera] al objetivo de una manera aún tan extrema, que éste sólo [fuera] capaz de triunfar sobre el otro reprimiéndolo, entonces el Estado tendr[ía] que emplear

\footnotetext{
${ }^{100}$ Schiller, Cartas ..., op. cit., pág. 125. Schiller pone un ejemplo muy claro: "Para reparar un mecanismo de relojería, el relojero detiene las ruedas, pero el mecanismo de relojería viviente que es el Estado ha de ser reparado en plena marcha, y eso significa cambiar la rueda mientras está en funcionamiento", id., págs. 125-127.

${ }^{101}$ Schiller, Cartas ..., op. cit., pág. 165.

${ }^{102}$ Schiller, Cartas ..., op. cit., págs. 133-135.

${ }^{103}$ Schiller, Cartas ..., op. cit, pág. 117.

${ }^{104}$ Schiller, Cartas ..., op. cit., pág. 135.

${ }^{105}$ Schiller, Cartas ..., op. cit., pág. 135.

${ }^{106}$ Schiller, Cartas ..., op. cit., pág. 147.
} 
contra sus ciudadanos la rigurosidad de la ley y, para no perecer ante una individualidad tan hostil, tendr[ía que aplastarla sin consideración alguna"108. Para Schiller, la única manera de resolver en la experiencia este problema político será por medio de "la vía estética [durch das ästhetische den Weg nehmen muss], porque es a través de la belleza [die Schönheit] como se llega a la libertad"109, a la libertad política, "la más perfecta de las obras de arte"110.

\section{AN ARTIST IN THE MONCLOA}

\section{Abstract}

In this text we try to reflecto $n$ the thread of Schiller's proposals on the needs to think politics beyond science and technology. Schiller's idea to conceive the statesman as an artista opens the field of political reflection to the philosophical world, which is the appropriate space to face the difficulties of our time.

Keywords: Natural State; Nature State; State; Physical Man; Moral Man and Nation.

\section{REFERENCIAS}

AZAÑA, M., La velada en Benicarló. Diálogo de la guerra de España, 1937, ed. de M. Aragón, Castalia, Madrid, 1974(1937)

CHATEAUBRIAND, Memorias de ultratumba, sel. y pról. de A. Ramoneda, trad. de J. Zamacois, Alianza, Madrid, 2003 (18481850)

HEGEL, G. W. F., "Primer programa de un sistema del idealismo alemán”, ¿invierno 179697?, en Escritos de juventud, ed., int. y notas de J. M. Ripalda, trad. de J. M. Ripalda y Z. Szankay, FCE, México, 1978 (17941801)

Fenomenología del Espíritu, trad. de W. Roces, Fondo de Cultura Económica, México, 1966 (1807)

Principios de la Filosofía del Derecho, trad. de J. L. Vermal, Edhasa, Barcelona, 1988 (1821)

Lecciones sobre la filosofía de la historia universal, pról. de J. Ortega y Gasset, adv. y trad. de J. Gaos (1928), Alianza, Madrid, 1980 (1830)

HOBBES, Th., Leviatán. La materia, forma y poder de un Estado eclesiástico y civil, trad., prólogo y notas de C. Mellizo, Alianza Editorial, Madrid, 1989 (1651)

JIMÉNEZ SÁNCHEZ, José J., Una comprensión monstruosa del derecho a decidir, ms., 2016

PLA, J., Dietarios, trad. de D. Ridruejo y G. de Ros, EspasaCalpe, Madrid, 2011 (1966, 1918).

\footnotetext{
${ }^{107}$ Schiller, Cartas ..., op. cit., pág. 151

${ }^{108}$ Schiller, Cartas ..., op. cit., pág. 135.

${ }^{109}$ Schiller, Cartas ..., op. cit., pág. 121.

${ }^{110}$ Schiller, Cartas ...., op. cit., pág. 117.
} 
SCHILLER, F., Kallias. Cartas sobre la educación estética del hombre, ed. bilingüe; est. intr. de J. Feijóo; trad. y notas de J. Feijóo y J. Seca, Anthropos, Barcelona, 1990 (17931795)

SCHMITT, C., The Leviathan in the State Theory of Thomas Hobbes. Meaning and Failure of a Political Symbol, trad. G. Schwab y E. Hilfstein, Greenwood Press, London, 1996 (1938)

Trabalho enviado em 18 de fevereiro de 2018.

Aceito em 24 de março de 2018. 